\title{
Patentes: flexibilidades del ADPIC como respuesta a la pandemia del COVID-19. Lecciones aprendidas y perspectivas de una política futura
}

$* * * *$

Magali Contardi

Universidad de Alicante

avv.mcontardi@gmail.com

Elisabet Vidal

Universidad Católica de Santa Fe

evidal@ucsf.edu.ar

Recibido: 30 de abril de 2021

Aceptado: 28 de mayo de 2021

\section{Resumen}

La emergencia sanitaria causada por la pandemia del COVID-19 ha dado lugar a un intenso debate sobre el rol de los derechos de propiedad industrial (PI) entre quienes sostienen que estos derechos pueden obstaculizar el desarrollo, la fabricación y la distribución de productos esenciales para contrarrestar los efectos de la pandemia y quienes, en sentido opuesto, argumentan que la protección de los derechos de PI es fundamental para el incentivo de la innovación y la transferencia de tecnología. En este contexto, el presente artículo, evidenciando ejemplos concretos referidos a la actual pandemia y otros ejemplos del pasado, tiene como objetivo analizar la manifestada colisión entre los derechos exclusivos de quienes son titulares de las patentes y el interés general de la sociedad en la disponibilidad y efectivo acceso en forma igualitaria a medicamentos esenciales en relación con las distintas medidas disponibles a nivel legislativo e internacional, y con las distintas iniciativas, como la propuesta de renuncia transitoria de los derechos de PI presentada a la Organización Mundial del Comercio por algunos países, actualmente 
en el debate internacional. Se concluye que la búsqueda del equilibrio debe pasar por la cooperación internacional, que establezca un delicado balance para satisfacer el interés por el acceso a tecnologías esenciales para contrarrestar la pandemia, salvaguardando los incentivos a la innovación y, a la vez, contribuyendo a delinear un cuadro reglamentario para hacerles frente a posibles crisis sanitarias futuras. El artículo está organizado del siguiente modo: la primera parte contextualiza el actual debate; la segunda analiza, desde una perspectiva histórica, la colisión entre derechos de PI y salud pública, evidenciando las flexibilidades proporcionadas por el ADPIC, como así también casos concretos de aplicación de licencias obligatorias. La tercera parte, partiendo de casos ocurridos durante la pandemia y que han dado lugar a debate público, estudia las flexibilidades del ADPIC, en particular las licencias obligatorias como medida de respuesta al COVID-19, describiendo las principales medidas adoptadas por algunos Estados, como así también iniciativas de tipo voluntario. La cuarta parte indaga las distintas posiciones en relación con el debate actual sobre las dos propuestas de suspensión generalizada de los derechos de PI en tiempos de pandemia. Por último, se delinean las conclusiones.

Palabras clave: innovación, patentes de invención, derecho a la salud, acceso a medicamentos esenciales, ADPIC, licencias obligatorias, emergencia sanitaria, COVID-19.

\section{Patents: TRIPS' Flexibilities as Response to COVID-19. Lessons Learned and Future Policy' Perspectives}

\section{Summary}

The health emergency triggered by the COVID-19 pandemic gave rise to an intense debate about the role of industrial property (IP) rights. Some argue that IP rights may hinder the development, manufacture and distribution of products essential to tackle the pandemic, others instead advocate in favour of a strong IP protection for incentivising innovation and technology transfer. Against this background, this paper highlights current and past controversial examples to shed light on the tension between IP right holders' and the general interest of society in having guaranteed effective and equal access to essential medicines. It further analyses the different measures available at international level, as well as the different initiatives currently under international debate, such as the proposal for the transitional waiver of IP rights introduced to the WTO by some Member States. The paper concludes that a compromise should be sought in international cooperation, striking a fair balance between both interests at stake, while contributing to delineate a regulatory framework to address potential future health crises. The paper is organised as follows: Part I. Contextualises the debate, Part II. Analyses from a historical viewpoint the tension between IP rights and public health, and 
discusses the flexibilities provided by TRIPS focussing on compulsory licenses. Part III. Building on publicly controversial examples of the pandemic it reviews the TRIPS' flexibilities, particularly the compulsory licenses as a response against COVID-19. It also examines the main legislative amendments and other measures adopted by some States, as well as other voluntary initiatives. Part IV. Explores the different position adopted by States in relation to two proposals seeking for a generalised suspension of IP rights in times of pandemic. Part V. It Draws conclusions.

Key words: innovation, patents, public health, access to essential medicines, compulsory licenses, pandemics, COVID-19.

\section{Patentes: flexibilidade do TRIPS em resposta à pandemia do COVID-19. Lições aprendidas e perspectivas para a política futura}

\section{Resumo}

A emergência sanitária gerada pela Pandemia COVID-19, tem provocado um profundo debate a respeito da atribuição dos direitos de Propriedade Industrial (PI), entre os quais mantém que, esses direitos podem obstaculizar o desenvolvimento, a fabricação e a distribuição de produtos essenciais para fazer frente aos efeitos da Pandemia. E também estáo aqueles, que no sentido oposto argumentam, que a proteção dos direitos de PI, é fundamental para o estímulo da inovação e transferência de tecnologia. Neste contexto, o presente artigo, demonstrando exemplos concretos com referências à atual pandemia e outros exemplos do passado; tem como objetivo o análise da manifestada colisão, entre os direitos exclusivos que desfrutam aqueles que são os detentores das patentes, e o interesse geral da sociedade, na disponibilidade e efetivo acesso de maneira igualitária aos medicamentos essenciais, em relação às diferentes medidas disponíveis tanto quanto com o legislativo ou o internacional. Assim como também as diferentes iniciativas, como por exemplo: a proposta de renúncia temporária dos direitos de PI aṕresentada à $\mathrm{OMC}$ por alguns países, atualmente em debate internacional. Conclui-se que a procura do equilíbrio tem que passar pela cooperaçáo internacional, que possa estabelecer uma delicada avaliação, para satisfazer o interesse pelo acesso a tecnologias essenciais para contrariar a pandemia, salvaguardando os estímulos para a inovação, e também contribuir para uma imagem regulatória, que possa fazer frente às possíveis crises sanitárias futuras.

$\mathrm{O}$ artigo esta organizado do modo seguinte: Parte 1: Contextualizar o atual debate. Parte 2: Fazer análise desde uma perspectiva histórica, da colisáo entre os direitos de PI e a saúde pública, evidenciando as flexibilidades oferecidas pelo ADPIC, como assim também casos específicos da aplicação de licenças forçosas. Parte 3: Partindo de casos acontecidos durante a pandemia, e que deram lugar ao debate público, faz análise das flexibilidades do ADPIC, em particular as licenças 
forçosas, como uma medida de resposta ao COVID-19; descrevendo as principais medidas adotadas por alguns Estados, como assim também iniciativas de tipo "voluntariado". Parte 4: Faz análise das diferentes posiçôes em relação ao debate atual, com respeito às propostas de suspensáo generalizada dos direitos de PI em tempos de pandemia. Parte 5: Esboça conclusóes.

Palavras-chave: inovação, patentes de invenção, direito à saúde, acesso a medicamentos essenciais, TRIPS, licenças compulsórias, emergência sanitária, COVID-19.

\section{Introducción}

A poco más de un año de que la Organización Mundial de la Salud (OMS) clasificara al virus SARS-CoV-2 ("COVID-19" о "coronavirus") como "pandemia” (Organización Mundial de la Salud [OMS], 2020a), al momento de redactar estas líneas, con más de 142557268 contagios y 3037398 fallecidos en el mundo (OMS, 2020a), ${ }^{1}$ el COVID-19 sigue produciendo efectos devastadores a escala mundial. ${ }^{2}$

Si bien en las últimas décadas los Estados han debido afrontar otras emergencias de salud pública, como las epidemias causadas por la gripe aviar, el (H1N1), el Ébola y el Zika, estas afectaron a parte de la población, especialmente en aquellos países en vías de desarrollo. La repentina aparición y la rápida propagación del virus COVID-19 en todo el mundo ha puesto en crisis no solo a los Gobiernos de países industrializados y en vías de desarrollo, sino también a la comunidad científica internacional, inicialmente debido a la inexistencia de vacunas o medicamentos para prevenirlo y curarlo, llegando incluso a generar escasez de equipos médicos esenciales, sobretodo en la primera "ola" de la pandemia, y, más recientemente, debido a la falta de disponibilidad de suficientes dosis de vacunas para ser distribuidas de manera equitativa entre países en vías de desarrollo y países desarrollados a bajo precio.

Por otra parte, cabe destacar que esta pandemia irrumpe en el

1 Datos proporcionados al 21 de abril de 2021.

2 No solo sanitarios: la fuerte desaceleración del comercio y de los viajes internacionales impacta negativamente en economías de todo el mundo, afectando especialmente a los más vulnerables económicamente. 
mundo en un momento de explosión de los conocimientos científicos (Desantes, 2020), ${ }^{3}$ es decir, en la era de la inteligencia artificial, el big data, los dispositivos contectados, la robótica, la genómica, la ciencia computacional y la biología estructural, que pueden ayudar a dar una rápida respuesta al desarrollo de tecnologías esenciales para contrarrestar los efectos causados por la emergencia. En este contexto, no sorprende que la pandemia del COVID-19 haya dado lugar a una carrera sin precedentes para desarrollar tratamientos, vacunas ${ }^{4}$ y otros tipos de tecnologías médicas, ${ }^{5}$ como programas informáticos (apps) para monitorear pacientes y número de contagios. ${ }^{6}$ En el Patent Index 2020 publicado por la Oficina de Patentes Europea, el sector tecnologías médicas, farmacéuticos y biotecnología encabezan las estadísticas de solicitudes de patentes, con un crecimiento del $19 \%$ respecto al año anterior. ${ }^{7}$

Sin embargo, la respuesta a la emergencia está indisolublemente ligada a la propiedad intelectual, ya que el desarrollo de estas tecnologías

3 Evidenciando que la Cuarta Revolución Industrial se caracteriza por una serie de nuevas tecnologías que están fusionando los mundos físico, digital y biológico, impactando en todas las disciplinas, economías e industrias.

4 Ya en enero de 2020 fue detectada la secuencia del genoma de COVID-19 y compartida con la comunidad científica internacional. Las autoridades de regulación coayudaron a agilizar las fases de ensayos clínicos, que normalmente llevan ańos (Cf. Cassatta, 2021; Milken Institute, 2021). Al mes de febrero de 2021, al menos siete vacunas habían sido aprobadas: Pfizer/BioNtech, Moderna, Johnson \& Johnson, Sputnik V, Sinopharm/ Beijing, Oxford/ Astrazeneca, Sinovac, las cuales han sido distribuidas de forma diversa en distintas partes del mundo (cf. Ritchie et al., 2021).

5 Por ejemplo, la empresa canadiense Draganfly desarrolló drones para detectar a las personas con síntomas de COVID-19, entre otros, para suministrar medicinas a hospitales y como herramientas de diagnóstico precoz (cf. Jones, 2020; McNabb, 2021; Morgan, 2021).

6 Por ejemplo, el grupo británico SDG desarrolló la aplicación Docdot, basada en tecnología de inteligencia artificial, que le permite al personal médico hacer un seguimiento virtual de las constantes vitales de los pacientes y detectar los síntomas de COVID-19, permitiendo a la vez recoger datos en tiempo real para obtener información actualizada sobre los casos confirmados (cf. Docdot Provides Healthcare Professionals, 2021).

7 Biotecnologías (+ 6,3\%), farmacéuticos (+ 10,2\%) y tecnologías médicas (+ 2,6\%) (cf. European Patent Office, 2020). 
y la asignación y distribución de los productos resultantes se rige por los derechos de propiedad intelectual. Estos regímenes influyen en la investigación y desarrollo $(\mathrm{I}+\mathrm{D})$ de invenciones, dan forma a las colaboraciones científicas y, en algunos casos, pueden condicionar la disponibilidad generalizada de nuevas tecnologías. De allí que, en el debate internacional para contrastar la emergencia, la comunidad internacional haya centrado la atención en el papel y en la función de los derechos de propiedad intelectual, poniendo en evidencia la necesidad de conciliar el interés público de dar una pronta respuesta a la propagación del virus con el interés privado de garantizar la eficacia de la protección de los derechos de propiedad intelectual, en particular de patentes.

La propiedad intelectual tiene por función ser un incentivo a la innovación (Maurer, 2015). Como es sabido, la ratio del derecho de patentes encuentra su apoyo en la premisa utilitarista (Fisher, 2001), según la cual garantizar un derecho temporalmente limitado a fin de compensar los esfuerzos intelectuales y económicos realizados para la obtención de una invención se traduce en beneficio social. Sin este derecho temporal, la libre competencia haría que el precio de los productos baje a los costos marginales, situación que les impediría a los titulares de los derechos de patentes recuperar los recursos invertidos. En esta dinámica, en la que los incentivos condicionan fuertemente la financiación de la $\mathrm{I}+\mathrm{D}$, existe el riesgo de que algunos productos permanezcan sin desarrollo o bien que este sea insuficiente si, desde una perspectiva económica, el retorno de la inversión realizada no es lo suficientemente atractiva (Rutschman, 2018). ${ }^{8}$

En este sentido, producir una vacuna conlleva un proceso largo y costoso, ya que requiere el uso de instalaciones y equipos con un alto grado de especialización (International Federation of Pharmaceutical Manufacturers \& Associations, 2019) para alcanzar un resultado óptimo. En su desarrollo intervienen diversos actores que deben invertir tiempo en investigación, afrontar los costos del desarrollo de principios activos, ${ }^{9}$ procurar la infraestructura necesaria para pro-

8 Existen, sin embargo, otros tipos de incentivos económicos distintos de las patentes para fomentar la innovación, como las subvenciones, los premios y los incentivos fiscales (cf. Lichtman, 2018).

9 En 2014, el costo de la investigación y el desarrollo de una nueva entidad 
ducirlos, realizar ensayos clínicos y seguir complejas técnicas de envasado y almacenamiento antes de que pueda ser utilizada en seres humanos. Por ejemplo, se han invertido alrededor de 8,2 billones de libras esterlinas para el desarrollo de la vacuna Oxford/AstraZeneca (el 97\%, financiado por fondos públicos); 2,25 billones de libras esterlinas en el desarrollo de la vacuna Pfizer/BioNTech, principalmente financiada con fondos privados; y 1,9 billones de libras esterlinas para la vacuna Moderna, financiada mayormente por fondos públicos (Hooker y Palumbo, 2020; Safi, 2021). Sin duda, los derechos exclusivos que ofrecen las patentes son importantes para incentivar a las empresas a invertir enormes recursos para alcanzar el fin deseado. Algunos sostienen que sin la perspectiva de la protección de la propiedad intelectual, la tecnología más avanzada y prometedora en la que se basan las vacunas contra el COVID-19 probablemente nunca se habría desarrollado (Mercurio, 2021). ${ }^{10}$

Combatir la pandemia significa el inmediato y asequible acceso a tratamientos, a las vacunas antes mencionadas y a otros dispositivos médicos. Sin embargo, debido a que en la dinámica del derecho de patentes el interés del público por la libre utilización de invenciones y el de los inventores por ver garantizado un plazo de exclusividad en el que puedan restringir el libre uso no pueden satisfacerse contemporáneamente, los fines de las políticas de incentivos en $\mathrm{I}+\mathrm{D}$ y los imperativos de salud pública se disocian, entrando en conflicto. En la perspectiva social, dar prioridad a la salvaguardia de los derechos de propiedad industrial es visto como un obstáculo al acceso a medicamentos esenciales y, en la perspectiva de los titulares de estos derechos, priorizar imperativos de salud pública es visto como una privación de otros derechos fundamentales, como lo es el derecho a la propiedad. ${ }^{11}$

química o biológica (molécula) se estimó en 1926 millones de euros (DiMasi et al., 2016).

10 Así se evidencia que el concepto de modificar cadenas específicas de ARNm sintético, la tecnología utilizada en las vacunas de Pfizer y Moderna, se introdujo por pmrimera vez en la década de 1990, pero que la versión ligeramente modificada para eludir las fallas en su uso no se descubrió hasta 2005, llegando a la fase de comercialización quince años más tarde (Isaacson, 2021).

11 Los derechos de propiedad intelectual también pueden considerarse derechos fundamentales, tal y como lo confirman la Carta de Derechos Fundamenta- 


\section{Derechos de patentes vs. derecho a la salud: una tensión constante}

La pandemia puso de manifiesto la dificultad de encontrar un equilibrio entre incentivar el desarrollo de nuevos medicamentos y tecnologías médicas a través de los derechos de patentes y garantizar la disponibilidad de estos en virtud de derechos fundamentales, como el derecho a la salud o, incluso, el mismo derecho a la vida.

Esta tensión entre derechos de exclusiva y derechos a la salud (Correa, 2002) no es nueva y ha suscitado no pocas controversias entre los distintos Estados miembros de la Organización Mundial del Comercio (OMC), ${ }^{12}$ manifestadas ya en sede de adopción del Acuerdo sobre los Aspectos de Derechos de Propiedad Intelectual relacionados con el Comercio (ADPIC).$^{13}$ Por ello, las flexibilidades proporcionadas por el ADPIC, como las licencias obligatorias de patentes, son de particular relevancia. Estas les permiten a los Estados miembros delinear el justo equilibrio entre estos intereses legítimos, que parecen ser, prima facie, irreconciliables.

les de la Unión Europea (UE) (artículo 17.2) y la jurisprudencia del Tribunal Europeo de Derechos Humanos.

12 Véanse: Australia, Determinadas medidas relativas a las marcas de fábrica o de comercio, indicaciones geográficas y otras prescripciones de empaquetado genérico aplicables a los productos de tabaco y al empaquetado de esos productos WT/DS467/23 (sobre la colisión entre el derecho a la salud y el derecho de marcas); Unión Europea c. India y Brasil - Confiscación de medicamentos genéricos en tránsito, WTIDS408/8 y WT/DS409 (derechos de patentes y salud pública).

13 Véase Anexo 1c. Acuerdo sobre los Aspectos de Derechos de Propiedad Intelectual relacionados con el Comercio (ADPIC). El ADPIC vincula la protección de las patentes y otros tipos de propiedad intelectual al comercio, imponiéndoles a los países miembros respetar los distintos derechos de PI y adoptar a tal fin instrumentos que hagan efectiva su observancia en todo el territorio nacional a cambio de mayor accesso a mercados extranjeros (Ragavan, 2012). Ya durante la negociación del acuerdo en la ronda de Uruguay, los países industrializados avocaban por la necesidad de adoptar un sistema "fuerte" o "estricto" de protección de los derechos de propiedad intelectual, mientras que los países menos desarrollados sostenían que ello sería contraproducente para la innovación local o el accesso a productos considerados esenciales, como los medicamentos (cf. Correa, 2002). 
En tal sentido, el artículo 31 del ADPIC, ${ }^{14}$ al aludir a "otros usos no autorizados por el titular de los derechos" (de patentes) les permite a los Estados limitar las prerrogativas de los titulares (de patentes) mediante el recurso a las licencias obligatorias (Organización Mundial del Comercio [OMC], 2020). ${ }^{15}$ En términos prácticos, ello implica que un Estado miembro del Acuerdo puede autorizar el uso de una invención (de producto o procedimiento) patentada a un tercero o a un organismo gubernamental sin el consentimiento del titular de la patente.

Esta norma establece una serie de condiciones para la concesión de licencias obligatorias, por las cuales se les otorga a los Estados miembros libertad para estipular los motivos por los que pueden concederse, reglamentar el procedimiento previsto para su aplicación y decidir la incorporación o no de la excepción en su derecho interno. ${ }^{16}$ En general, el titular de la patente recibe una "remuneración adecuada” por el uso de su invención, aunque esta cantidad suele ser inferior a la que podría exigir en una transacción en condiciones de mercado. Además, quien la requiera debe intentar primero obtener un acuerdo con el titular de la patente "en términos comerciales razonables". Sin embargo, la norma dispone que durante "una emergencia nacional u otras circunstancias de extrema urgencia” es suficiente notificar al titular de la patente "tan pronto como sea razonablemente posible" sin la necesidad de intentar previas negociaciones con él.

Asimismo, la Declaración relativa al acuerdo sobre los ADPIC y la salud pública adoptada durante la Conferencia Ministerial de la OMC celebrada en Doha en 2001 (OMC, 2001) ${ }^{17}$ afirma la vo-

14 Artículo 31 del ADPIC.

15 Define "Compulsory licensing is when a government allows someone else to produce a patented product or process without the consent of the patent owner or plans to use the patent-protected invention itself".

16 Son 156 los países que tienen incorporada en sus legislaciones nacionales sobre patentes la licencia obligatoria como limitación al derecho del titular de una patente (Standing Committee on the Law of Patents, 2019).

17 La Declaración de Doha, adoptada por la Conferencia Ministerial el 14 de noviembre de 2001, es una manifestación de un compromiso entre visiones contapuestas, que representa sin dudas un punto de inflección en el comercio 
luntad de los Estados miembros de permitir una mayor flexibilidad en la adopción de licencias obligatorias. ${ }^{18}$ En una decisión de fecha 30 de agosto de 2003 referida a la aplicación del párrafo 6 de la Declaración de Doha (Correa, 2005; OMC, 2003), ${ }^{19}$ los miembros de la OMC establecieron un mecanismo de exención al artículo 31(f) del ADPIC que condicionaba la concesión de licencias obligatorias al suministro para el mercado local, ${ }^{20}$ porque si bien el artículo 31 del ADPIC les permitía a los países conceder licencias obligatorias, el funcionamiento práctico era ineficaz, ya que la mayoría de los países que las otorgaban carecían de la capacidad y conocimientos necesarios para producir los medicamentos objeto de la licencia. De allí que, según la regla, ahora codificada en el artículo 31 bis del

internacional. Su contenido no solo reafirma que un sistema de comercio basado en reglas jurídicas debe ser compatible con los intereses de la salud pública, sino que va más allá, convirtiendo la protección de la salud pública en un propósito claramente expresado en el Acuerdo. Los países en desarrollo buscaban que se adoptaran medidas en el marco de la OMC para garantizar que el Acuerdo sobre los ADPIC no socavara el "[...] derecho de los Miembros de la OMC a formular sus propias políticas de salud pública y a aplicarlas mediante la adopción de medidas que protejan la salud pública”. Véase la comunicación del Grupo Africano, Barbados, Bolivia, Brasil, Cuba, República Dominicana, Ecuador, Honduras, India, Indonesia, Jamaica, Pakistán, Paraguay, Filipinas, Perú, Sri Lanka, Tailandia y Venezuela: "Los ADPIC y la salud pública”, documento de la OMC (disponible en: https:// www.wto.org/spanish/tratop_s/trips_s/paper_develop_w296_s.htm). La posición diametralmente opuesta era aquella asumida por los Estados Unidos (IP/C/M/31). La Unión Europea adoptó, en cambio, una posición intermedia (Declaración CE, IP/C/W/280), dispuesta a contribuir "de modo constructivo en cualquier debate relativo a la interpretación de esas disposiciones".

18 El párrafo 6 de esta declaración afirma: "Reconocemos que los miembros de la OMC con capacidades de fabricación insuficientes o inexistentes en el sector farmacéutico podrían tener dificultades para hacer un uso eficaz de las licencias de oficio en el marco del Acuerdo sobre los ADPIC. Encomendamos al Consejo de los ADPIC que encuentre una solución rápida a este problema y que informe al Consejo General antes de finales de 2002" (Abbott, 2002).

19 Cfr. Organización Mundial de la Salud (2002), que señala el problema de las economías de escala al que se enfrentan los países pequeños y pobres al producir medicamentos bajo licencia obligatoria.

20 Artículo 31 (f) del ADPIC. 
Acuerdo ADPIC, ${ }^{21}$ si un país no puede garantizar el acceso a los medicamentos necesarios a precios asequibles, podrían ser producidos bajo licencia obligatoria por fabricantes de medicamentos de otros países e importados a ese país que no tiene capacidad para producirlos por sí mismo. ${ }^{22}$ Sin embargo, esta norma ha sido criticada, entre otros motivos, por las dificultades que la aplicación práctica comporta (Binctin et al., 2020; Correa y Velázquez, 2019). De hecho, solo una vez ha sido utilizada. ${ }^{23}$

La excepción de licencias obligatorias del artículo 31 del ADPIC ha sido invocada en el pasado en un número limitado de casos por los países en desarrollo para hacer frente a crisis sanitarias graves. Por ejemplo, en Zambia, Eritrea, Ghana, Malasia, Indonesia, Sudáfrica (Akpotaire, 2010) y Brasil ${ }^{24}$ fue utilizada para permitir el acceso a medicamentos patentados producidos para combatir la propagación exponencial del virus HIV. En 2005, en el contexto de la emergencia sanitaria de la gripe aviar, Argentina anunció la intención de conceder una licencia obligatoria ${ }^{25}$ para fabricar el antiviral Tamiflu, pa-

21 En 2005, la decisión de Doha sobre la exención del artículo 31(f) del ADPIC se transformó en una enmienda permanente del Acuerdo sobre los ADPIC como artículo 31 bis, que entró en vigor en enero de 2017.

22 Sin embargo, varios países -además de la Unión Europea- han optado por la exclusión (waiver) de esta previsión. No obstante ello, en la Unión Europea, el Reglamento (CE) no 816/2006, de 17 de mayo de 2006, relativo a la concesión de licencias obligatorias sobre patentes para la fabricación de productos farmacéuticos destinados a la exportación a países con problemas de salud pública, aplica la decisión adoptada el 30 de agosto de 2003 por la OMC a raíz de la Declaración de Doha.

23 En 2007 para las exportaciones de la combinación antirretroviral del VIH Apo-TriAvir, fabricada por la empresa canadiense Apotex, destinada a Ruanda. El suministro del medicamento a Ruanda tardó más de un año en llegar al país (Ramanujam y Goyal, 2014).

24 Para un análisis sobre el uso de licencias obligatorias en Brasil, véase: Documento C. 8828, Additional inputs for the preparation of documents to the 30th Session of the Standing Committee on the Law of Patents del 14/02/2019 (Champ y Attaran, 2002).

25 La ley de patentes argentina regula la aplicación de las licencias obligatorias en el Capítulo VII (artículo 42) "Otros usos sin autorización del titular de la patente”. El artículo 45 de la ley específicamente establece la emergencia 
tentado por la farmacéutica Roche, único fármaco que podía ser usado en humanos en caso de una pandemia de la gripe aviar. Sin embargo, más tarde se determinó que las patentes sobre el Tamiflu no habían sido concedidas en Argentina, por lo que no fue necesaria la licencia (Argentina pide licencia compulsiva..., 2005).

Además, algunos países en vías de desarrollo han aplicado licencias obligatorias en relación con patentes de medicamentos oncológicos, a fin de garantizar su disponibilidad a un precio accesible. En 2012, por ejemplo, el fabricante de medicamentos genéricos de la India (Rathod, 2017) Natco obtuvo una licencia obligatoria para el fármaco Sorafenib, utilizado para el tratamiento contra el cáncer de hígado y de riñón, después de que la oficina de patentes de ese país dictaminara que Bayer AG, la titular de la patente del Sorafenib, no había hecho lo suficiente para poner el medicamento a disposición de los ciudadanos de la India. ${ }^{26}$ En virtud de la licencia, Natco propuso vender el medicamento por un $97 \%$ por debajo del precio de Bayer (Bonadio, 2012).

En la Unión Europea, la aplicación ha sido casi inexistente. En 2017, el Tribunal Federal Supremo alemán le concedió a la farmacéutica Merck una licencia obligatoria para la comercialización del fármaco Raltergravir, un principio activo patentado por la compañía japonesa Shionogi, utilizado en la fabricación de medicamentos para inhibir la propagación del virus HIV. En dicha controversia, el Tribunal Federal ${ }^{27}$ estimó que el interés público justificaba la concesión de la licencia, debido a que la salud de muchas personas estaba en peligro, incluida la de mujeres embarazadas, lactantes y niños, así como también pacientes recién infectados y pacientes crónicos. Sin embargo, más recientemente, el Tribunal Federal Supremo alemán

sanitaria nacional como motivo válido para recurrir a esta excepción.

26 Véase: Natco Pharma Ltd. v. Uol \& Ors.; M/S Cancer Patients Aid Association v. Uol \& Ors. En la controversia en cuestión, el juez nacional priorizó derechos fundamentales, como el derecho a la vida, a la salud, a la dignidad humana, legitimando las cláusulas de limitación de la propiedad intelectual previstas en el ADPIC.

27 Véase: Sentencia Tribunal Federal Supremo Alemán, BGH, 11.07.2017; XZB 2/17. Para las decisiones de primer y segundo grado (Landgericht; Oberlandgericht); cfr. Hohne (2019). 
rechazó una solicitud de licencia obligatoria, privilegiando los intereses del titular de la patente. ${ }^{28}$

\section{Flexibilidades del ADPIC: de las licencias obligatorias a medidas voluntarias en respuesta al COVID-19}

Por un lado, es razonable afirmar que la pandemia del COVID-19 constituye una situación de emergencia nacional y/o de extrema urgencia en el sentido del artículo 31 del ADPIC, que permite a los Estados miembros autorizar la concesión de licencias obligatorias para facilitar la producción y exportación de medicamentos, tecnologías o vacunas para la prevención y el tratamiento de la pandemia. Por otro, debe tenerse en cuenta que la Declaración de Doha ${ }^{29}$ afirma que los Estados miembros tienen total discrecionalidad para determinar las bases de concesión de una licencia obligatoria. De allí que se hace necesario -siempre- analizar las condiciones y requisitos específicos establecidos por la legislación de patentes de cada país. ${ }^{30}$

28 En junio de 2019, el Tribunal Federal Supremo alemán rechazó la solicitud de Sanofi de una licencia obligatoria preliminar sobre la patente de Amgen EP 2215 214, que protege un principio activo (alirocumab), utilizado para inhibir la proteína PCSK9 y disminuir el nivel de colesterol. De conformidad con el artículo 24 de la Ley de Patentes de Alemania (Patentgesetz, PatG; disponible en: https://www.gesetze-im-internet.de/patg/), puede concederse una licencia obligatoria de patente si el posible infractor ha hecho esfuerzos razonables para obtener una licencia en condiciones razonables -pero no ha tenido éxito- y si subsiste un interés público. En este caso, el Tribunal Federal Supremo alemán no concedió la solicitud de licencia obligatoria de Sanofi, porque consideró que existía suficiente interés público en la disponibilidad del medicamento, pero que los esfuerzos de Sanofi por obtener una licencia de Amgen en el período previo a la demanda por infracción de patentes fueron inadecuados. Véase Sentencia del Tribunal Federal Supremo $B G H, 04.06 .2019$ - XZB 2/19.

29 Artículo 5 (b): "Cada Miembro tiene el derecho de determinar lo que constituye una emergencia nacional u otras circunstancias de extrema urgencia”. El artículo 5 (c) aclara, además, que las crisis de salud pública, incluidas las relacionadas con el VIH/SIDA, la tuberculosis, el paludismo y otras epidemias, pueden constituir una emergencia nacional $\mathrm{u}$ otras circunstancias de extrema urgencia.

30 Para un análisis profundizado sobre las diferencias en las leyes sobre las licen- 
Italia fue uno de los países que tuvo que hacer cuentas con el propio sistema. ${ }^{31}$ En el pleno de la pandemia, el Hospital de Chiari, en la provincia de Brescia, uno de los territorios italianos mayormente afectados en la primera "ola", denunció que debido al repentino aumento de hospitalizaciones por infección de COVID-19 no contaban con suficientes válvulas para los respiradores de terapia intensiva y que el productor, la sociedad britanica Intersurgical, no podía garantizar el suministro inmediato. Teniendo en cuenta que dichas válvulas eran un componente esencial de los respiradores utilizados para tratar a los pacientes, una empresa italiana, Isinnova, aplicando ingeniería inversa, logró reproducir cien válvulas con tecnología 3D en 24 horas (Vinci, 2020), que fueron entregadas inmediatamente al hospital de Brescia y a otros hospitales que se encontraban en análogas condiciones de emergencia para, de este modo, poder salvar vidas. ${ }^{32}$

Debido a que las válvulas reproducidas estaban protegidas por los derechos de patente de la sociedad Intersurgical, la reproducción no autorizada por parte de la sociedad Isinnova constituía, al menos formalmente, una infracción a los derechos del titular de la patente. Por ello, este caso italiano dio lugar a un intenso debate sobre la posibilidad de invocar las normas sobre las licencias obligatorias ${ }^{33}$ para

cias obligatorias de los distintos Estados miembros de la Unión Europea, cfr. European Patent Office (2018)

31 En marzo 2020, el virus se difundió rapidamente en dicho país, provocando la saturación de los hospitales, terapias intensivas y carencia de dispositivos médicos, en particular de respiradores.

32 De modo análogo, la sociedad italiana Isinnova desarrolló respiradores utilizando las máscaras de buceo de Decathlon, que patentó en italia, declarando que la patente quedará libremente a disposición del público (Easy Covid-19..., 2020); la sociedad Medtronic compartió las especificaciones de diseño de uno de sus ventiladores, junto con una licencia que les permitía a otros fabricar diseños utilizando esas especificaciones durante la crisis (Jordan y Weispfenning, 2020).

33 Se debatió, además, sobre la posibilidad de invocar el estado de necesidad, previsto en el artículo 2045 Código Civil italiano, o la excepción de la utilización de la patente con fines no comerciales prevista en el artículo 68 del CPI (considerando que Isinnova donó las válvulas a los hospitales) e, incluso, se debatió sobre la posibilidad de invocar el principio de proporcionalidad, de conformidad con el párrafo 6 del artículo 124 de la CPI, que exige que la 
justificar la reproducción no autorizada de las válvulas. En Italia, los artículos 70-74 del Código de la Propiedad Industrial (CPI) ${ }^{34}$ regulan dos supuestos en los que pueden concederse licencias obligatorias. En primer lugar, en el caso de que durante un cierto período de tiempo (3 años a partir de la emisión o 4 ańos a partir de la presentación de la patente) el titular de la patente no la haya puesto en uso o cuando el uso sea manifiestamente desproporcionado con respecto a las necesidades del país. En segundo lugar, se puede conceder una licencia obligatoria cuando la puesta en uso o aplicación de una invención patentada (denominada "patente dependiente") no es posible sin violar los derechos de una patente anterior de un tercero (denominada "patente dominante"); en este caso, la licencia solo puede concederse en la medida -estrictamente necesaria- para explotar la patente dependiente y siempre que la invención relativa represente un progreso técnico y económico con respecto al objeto de la patente dominante. En tal sentido, cabe mencionar que cada Estado miembro conserva la facultad de determinar lo que constituye una situación de emergencia nacional o de extrema urgencia, y en Italia una emergencia sanitaria no está expresamente contemplada en el código de propiedad industrial. ${ }^{35}$

En última instancia, la sociedad británica Intersurgical nunca demandó a la sociedad italiana Isinnova por la infracción de sus derechos de patente sobre la válvula. Si lo hubiese hecho, el ejercicio de este derecho se consideraría legítimo. Sin embargo, cabe preguntarse

autoridad judicial en la cuantificación del daño por infracción de los derechos de patente realice un balance preliminar de los intereses. En virtud de tal norma, el juez está llamado a evaluar, basado en las circunstancias concretas de cada caso en examen, la gravedad de la violación, teniendo en cuenta también los intereses en juego, incluido el interés público general o a la necesidad de protección de los derechos fundamentales (Ramacciotti y Fratti, 2020).

34 Decreto Legislativo No 30 del 10 de febrero de 2005 y sucesivas modificaciones.

35 En el año 2016 había sido presentada una propuesta de reforma para introducir la posibilidad de conceder licencias obligatorias en caso de extrema urgencia, con particular referencia a una emergencia sanitaria. Véase: propuesta de Ley 4149 del 16 de noviembre de 2016 (disponible en: https://www. camera.it/leg17/995?sezione=documenti\&tipoDoc=lavori_testo_pdl\&idLegislatura=17\&codice=17PDL0047170). 
si en tiempos de emergencia sanitaria dicha decisión hubiese sido éticamente correcta. No debe olvidarse que, en definitiva, el bienestar social es el fundamento del derecho de patente y que la promoción de la innovación para el bienestar social es, además, un objetivo primordial del ADPIC. ${ }^{36}$

A raíz de este y otros casos controvertidos, ${ }^{37}$ se abrió un intenso debate respecto a la necesidad de adecuar las legislaciones sobre licencias obligatorias. Tal como el caso italiano demuestra, la pandemia no afecta únicamente a los países menos desarrollados, sino también a las principales economías del mundo. De allí que varios países hayan cambiado su posición respecto a las licencias obligatorias y hayan aprobado leyes específicas para facilitar la concesión y así poder producir medicamentos o productos patentados para hacerle frente a la emergencia del COVID-19.

En tal sentido, Alemania aprobó el 28 de marzo de 2020 la Ley de Prevención y Control de Enfermedades Infecciosas en los Seres Humanos, ${ }^{38}$ que introduce la posibilidad de emitir una licencia obligatoria "en interés del bienestar público o de la seguridad pública"39 en todos aquellos casos en los que el Parlamento Alemán (Bundestag) declare una epidemia nacional.

Asimismo, el 23 de marzo de 2020, Francia promulgó la Ley

36 El artículo 7 del ADPIC señala que la protección de la propiedad intelectual debe satisfacer el objetivo de "promover la innovación tecnológica y la transferencia y diseminación de tecnología, en beneficio recíproco de productores y usuarios, contribuyendo al bienestar social y económico y al equilibrio de derechos y obligaciones".

37 Sobre la controversia Gilead/Instituto Wuhan de Virologia en relación con el uso y patentes de segundo uso del fármaco Remdesivir para tratar el COVID-19, véase Choy y Lo (2020).

38 Cf. Bundesministerium der Justiz und für Verbraucherschutz (2020).

39 Artículo 13(1) de la Ley de Patentes alemana (PatentGesetz). Cabe aclarar que mientras que una licencia obligatoria en virtud del artículo 24 de la Ley de Patentes alemana es concedida por el Tribunal Federal en un caso individual a favor de un licenciatario determinado, el artículo 13 1) establece que el Gobierno Federal y el Ministerio Federal de Salud pueden ordenar que una patente no produzca efectos, lo que significa que su titular no puede prohibir los usos de la invención patentada, que son objeto de la orden del Gobierno o del Ministerio de la Salud. 
2020-290, ${ }^{40}$ que introduce el artículo L.3131-15 en el código de salud pública de dicho país, que le permite al primer ministro controlar temporalmente los precios de los productos y "adoptar las medidas necesarias” para poner a disposición de los pacientes los medicamentos pertinentes, incluida la posibilidad de autorizar la comercialización de productos genéricos en el territorio francés antes de la expiración de las patentes, si fuera necesario (Dhenne, 1 de mayo de 2020). Algunos consideran estas medidas adoptadas demasiado excesivas, llegando a caracterizarlas como una expropiación y no ya una licencia obligatoria. ${ }^{41}$ Mientras tanto, el parlamento francés -en medio de criticismos y visiones contrapuestas- se prepara para discutir la nueva propuesta de ley, presentada el 8 de abril de 2021, que sugiere ampliar el alcance de las licencias obligatorias a las solicitudes de patentes, como así también a todos los conocimientos técnicos necesarios para la fabricación del medicamento (know how). ${ }^{42}$

De modo análogo, Canadá reformó su legislación ${ }^{43}$ para facilitar la concesión de licencias obligatorias en casos de emergencia sanitaria, permitiéndole al Gobierno conceder una licencia sin negociar primero con el titular de los derechos de patente, e incluso dicha licencia podrá concederse aunque el titular de la patente sea capaz de fabricar, utilizar y vender la invención patentada.

En América Latina, Chile -a través de la Resolución 896/2020 (Instituto Nacional de Propiedad Intelectual de Chile, 2020)- estableció la posibilidad de otorgar licencias no voluntarias contempladas en el artículo 51 No 2 de la Ley 19039 de Propiedad Intelectual, con

40 LOI n $^{\circ}$ 2020-290 du 23 mars 2020 d'urgence pour faire face à l'épidémie de covid-19.

41 La amplitud de la disposición normativa comporta una privación de la propiedad, con consiguiente alteración en el equilibrio del sistema de incentivos de los derechos de propiedad intelectual (Schötz y Rapela, 2020).

42 Texto no 524, 2020-2021 presentado por el Sr. Ronan Le Gleut el 8 de abril de 2021.

43 Ley C-13 sobre Medidas en Respuesta a la Emergencia COVID-19, aprobada el 25 de marzo. La ley establece que si el Ministro Federal de Salud considera que existe una emergencia de salud pública, el Comisionado de Patentes puede permitirle al Estado canadiense producir, vender y utilizar una invención patentada. 
el objeto de facilitar el acceso y disponibilidad a los medicamentos y tecnologías para la prevención, tratamiento y cura del COVID-19, poniendo en cabeza del Instituto Nacional de Propiedad Industrial el trámite y contralor de aquellas solicitudes de patentes, patentes concedidas $\mathrm{u}$ otros derechos industriales que puedan restringir su importación o producción nacional que afecten vacunas, medicamentos, diagnósticos, dispositivos, suministros y otras tecnologías útiles para la vigilancia, prevención, detección, diagnóstico y tratamiento derivado de la rápida propagación del virus.

Por su parte, en la República Federativa del Brasil, en casos de máxima emergencia o interés público graves, se permite la implementación de licencias obligatorias ${ }^{44}$ previo cumplimiento de las condiciones establecidas - para estas circunstancias- en la normativa vigente, ${ }^{45}$ ya que son consideradas instrumentos de excepción y no pueden ser utilizadas como regla, debiéndose evitar en la medida de lo posible (Regattieri Oliveira, 2020). Su legitimidad tiene fundamento constitucional desde el año 1988, ya que las patentes son consideradas derechos de propiedad, aunque tienen condicionada y limitada su vigencia a la función social que deben desarrollar en la medida en que se presenten como válidas desde el punto de vista social y económico y sean tecnológicamente útiles para el país (Zucoloto et al., 2020). Así, para lograr que la ejecución de las licencias obligatorias sea eficiente y evitar normas y prerrequisitos excesivos, actualmente vigentes en el país, se presentaron tres proyectos de ley ${ }^{46}$ que buscan establecer disposiciones legales acerca de la concesión de permisos obligatorios otorgados por causa de emergencia nacional o interés público, así como medidas que faciliten el acceso a las tecnologías y productos necesarios para combatir la enfermedad causada por la rápida propagación del virus (Zucoloto et al., 2020). Otra medida adoptada por Brasil es que, en virtud de la Orden 149/2020, del 7 de abril de 2020 al 30 de junio de 2021 (OMC, 2020), el Instituto Nacional de la Propiedad Industrial de Brasil les dará prioridad al examen de las solicitudes de patente relacionadas con innovaciones que puedan utilizarse para luchar contra el COVID-19.

44 Ley de Propiedad Industrial 9279/1996, artículos 68 a 74.

45 Decreto 3201/1999, artículo 7.

46 PL 1.184 / 20, PL 1.320 / 20 y PL 1.462 / 20. 
En el caso de la República Argentina, la normativa adoptada para declarar la emergencia sanitaria ${ }^{47}$ se considera marco suficiente para otorgar licencias obligatorias para garantizar el derecho de explotación de patentes ${ }^{48}$ y así facilitar el acceso a vacunas, medicamentos, diagnósticos, dispositivos, suministros y otras tecnologías útiles para la vigilancia, prevención, detección, diagnóstico y tratamiento de personas infectadas por el coronavirus (COVID-19) en todo el territorio, por razones de salud pública o emergencia sanitaria, de conformidad con lo establecido en el ADPIC. ${ }^{49}$

En lo que al punto analizado respecta, sería aplicable el artículo 45 del Decreto 260/1996, ya que -dado como está planteada la cuestión- el Poder Ejecutivo Nacional podría disponer la explotación de ciertas patentes mediante el otorgamiento del derecho de explotación por motivos de emergencia sanitaria o seguridad nacional (licencia obligatoria), debiendo su alcance y duración encontrarse limitado a los fines de la concesión, la cual podría - de todas formasotorgarse a un tercero, aunque de forma no exclusiva. Asimismo, resultan también de aplicación tanto el artículo 47 de la Ley 24481 como el artículo 47 de su decreto reglamentario, en tanto ofrecen reglas generales que se deben cumplir en caso de que el Estado otorgue una licencia obligatoria por la causal de emergencia sanitaria, debiéndose esta limitarse -en su alcance y duración- a los fines para los que hayan sido autorizados y podrán retirarse si las circunstancias que dieron origen a esa autorización se hubieran extinguido y no

47 Ley 27541 de emergencia pública, en particular sus artículos 1, 2, inciso f y su Título IX: Emergencia sanitaria (artículos 64 y 85); Decreto Nacional de Urgencia 260/2020 del 12 de marzo de 2020 (en particular sus artículos $2,6,10,11,14,20$ y 22) y las normas complementarias respectivas a estas disposiciones.

48 Contempladas en los artículos 45 y 47 de la Ley 24481 de Patentes de Invención y Modelos de Utilidad y en los artículos 45 y 47 de su Decreto reglamentario 260/1996.

49 Artículo 31(b) del ADPIC, enmendado por el Protocolo del 6/12/2005 -tratados internacionales aprobados por la leyes 24425 y 26662, respectivamente, vigentes en Argentina- y por la Declaración de Doha de la Asamblea General de la OMC de 2001, relativa al Acuerdo ADPIC y la Salud Pública (cf. Honorable Cámara de Diputados de la Nación, 2020). 
fuera probable que vuelvan a surgir, facultándose al Instituto Nacional de la Propiedad Industrial para examinar estas circunstancias (Honorable Cámara de Diputados de la Nación, 2020)..$^{50}$

Por otra parte, aunque Israel no ha aprobado ninguna legislación específica, ha tomado la medida más contundente entre los países desarrollados al conceder una licencia obligatoria relacionada con el COVID-19. El 18 de marzo 2020, el ministro de Salud y el fiscal general de Israel concedieron una licencia obligatoria en virtud de los artículos 103-104 de la Ley de Patentes ${ }^{51}$ para permitir la importación de la India ${ }^{52}$ de una versión genérica del fármaco Kaletra, protegido por la patente de la sociedad AbbVie Inc., para su uso en el tratamiento de pacientes con coronavirus.

En sentido opuesto a los mecanismos "coercitivos" excepcionales disponibles en el ADPIC, se colocan algunos esfuerzos voluntarios con el fin de permitir la cooperación de la industria en respuesta al COVID-19. Así, en el mes de mayo de 2020, la OMS lanzó la iniciativa COVID-19 Technology Access Pool (C-TAP) (Acceso Mancomunado a Tecnología contra la COVID-19) (OMS, 2020c), es decir, un consorcio de patentes que permite a terceros adquirir licencias no exclusivas de la propiedad intelectual necesarias para

50 De todas formas, el Instituto Nacional de la Propiedad Industrial (INPI), desde el 13 de abril hasta el 30 de agosto, suspendió todos los plazos de este tipo de licencias -en una primera etapa-, prorrogada después a través de diferentes resoluciones (Resolución INPI 34/2020, BO 13/04/2020; Resolución INPI 37/2020, BO 28/04/2020; Resolución INPI 42/2020, BO 12/05/2020; Resolución INPI 47/2020, BO 27/05/2020; Resolución INPI 51/2020, BO 09/06/2020; Resolución INPI 69/2020, BO 09/06/2020; Resolución INPI 78/2020, BO 21/07/2020; Resolución INPI 109/2020, BO 05/08/2020; Resolución INPI 116/2020, BO 19/08/2020). Cf. OMC (2020).

51 Ley 5727 de 1967.

52 Kaletra es un fármaco utilizado para el tratamiento del HIV. La patente de AbbVie para Kaletra en Israel expira en 2024, mientras que en otros países, como la India, ya ha expirado. Por ello, Israel autorizó la importación, limitando la autorización al uso del fármaco para tratamiento experimental en pacientes con COVID-19 (Joffre, 2020). En última instancia, la farmacéutica AbbVie manifestó que no hará valer sus derechos de patentes sobre el fármaco Kaletra, debido a que su eficacia estaba siendo evaluada en varios ensayos clínicos para tratar pacientes con COVID -19 (Cf. Mancini y Kuchler, 2020). 
desarrollar medicamentos, vacunas y diagnósticos anti COVID-19. $\mathrm{La}$ iniciativa fue originariamente presentada por el Gobierno de Costa Rica, ${ }^{53}$ a raíz de la preocupación manifestada de que algunos productos y medicamentos esenciales para el tratamiento y prevención del COVID-19 pudiesen no ser accesibles para las poblaciones menos desarrolladas. $\mathrm{Al}$ mismo tiempo, la OMS lanzó además una solidarity call (OMS, 2020e), ${ }^{54}$ una especie de repositorio de recursos vinculados al COVID-19, en la que invita a sujetos públicos y privados a compartir los resultados de la investigación bajo licencias abiertas que garanticen el libre acceso y el uso y la redistribución equitativa de conocimientos científicos, datos de ensayos clínicos y otra información necesaria. Iniciativas análogas han sido promovidas por sujetos privados. ${ }^{55}$

Así, mediante el intercambio abierto de información científica y datos, muchas empresas podrán beneficiarse de la información que necesitan para desarrollar nuevas tecnologías y productos, reduciendo sus costes (McGahan et al., 2020). ${ }^{56}$ No obstante ello, su eficacia puede ser limitada, dada la voluntariedad de la adhesión, y podría dejar fuera a los titulares de patentes importantes o patentes dependientes para el desarrollo de un producto, como así también otras

53 A la fecha, han manifestado la adhesión a la iniciativa países en desarrollo que no tienen una elevada capacidad tecnológica de producción o de distribución, como así también varias organizaciones no gubernamentales (Letter to Dr Tedros Adhanom Ghebreyesus, 2020).

54 Otra iniciativa promovida por la OMS es la COVAX, con el objetivo de facilitar la distribución de vacunas (OMS, 2020b).

55 Por ejemplo, Wellcome Trust (Carr, 2020), en el que un grupo de editoriales científicas y médicas se comprometieron a poner a disposición de los interesados todas las publicaciones de investigación relacionadas con el $\mathrm{CO}$ VID-19; Open COVID Pledge (OCP), una plataforma estandarizada de licencias para patentes y derechos de autor que se lanzó el 7 de abril de 2020, que cuenta con la adhesión de Intel, Microsoft, Facebook, Uber, Amazon, Hewlett-Packard Enterprise, Sandia National Laboratory y otros titulares de patentes (cf. Peters, 2020), entre otros.

56 A través de iniciativas como el Open COVID Pledge, las empresas empezaron a ofrecer licencias gratuitas de su propiedad intelectual con el fin de luchar contra la pandemia. 
limitaciones derivadas de la legislación antitrust (Contreras, 2021) ${ }^{57}$ que podrían surgir en relación con la agregación de patentes.

\section{La propuesta a la OMC sobre una "renuncia" temporal a los derechos de propiedad intelectual}

Del análisis esbozado emerge que tanto los Estados como la comunidad científica y las empresas se están movilizando para hacer frente a la emergencia, adhiriendo a medidas voluntarias, como las antes mencionadas. Por otro lado, como se ha podido ver, el ADPIC ya proporciona algunas excepciones a las prerrogativas del titular de una patente, tales como las licencias obligatorias, que pueden facilitar el desarrollo, la producción y la distribución de medicamentos y tecnología médica esencial a bajo costo para afrontar la pandemia.

No obstante ello, se ha puesto de manifiesto que estos mecanismos, en particular las flexibilidades del ADPIC, podrían no ser suficientes dada la actual extensión de la emergencia, sobre todo a raíz de la complejidad inherente a la producción de vacunas u otras tecnologías necesarias. En tal sentido, cabe recordar que estos productos no solo están protegidos por derechos de patentes, sino que también pueden ser sujetos a derechos de autor (como el caso de aplicaciones para el rastreo de casos de COVID-19), diseños (respiradores o sus partes) o derecho de marcas (una vacuna). Además, hay otras disposiciones del ADPIC que condicionan la (efectiva) capacidad de los fabricantes de productos farmacéuticos para producir vacunas, tratamientos, diagnósticos y dispositivos médicos, como lo son los datos de prueba, el know how y que están protegidos por el artículo 39 del ADPIC (Wilkof, 2020). Ninguno de estos derechos de exclusiva quedarían comprendidos en la excepción de la licencia

57 Evidenciando que los patent pools se consideraron activamente en respuesta a otras emergencias - como la de la gripe aviar de 2009- y que la OMS, ya en 2011, inició una serie de actividades para explorar la viabilidad de agrupar las patentes relacionadas con las tecnologías de salud pública; sin embargo, estas medidas tuvieron poca repercusión práctica porque, en ultima instacia, los patent pool consisten en una agregación de patentes, que pueden dar lugar a prácticas anticompetitivas. 
obligatoria. De allí que la falta de autorización a su uso o la falta de acceso a estos obstaculizarían la eficacia de una licencia obligatoria concedida solo con respecto a los derechos de patentes.

Con el fin de hacerle frente a esta problemática, algunos autores (Abbott, 2020) sostienen la posibilidad de invocar las excepción relativa a la seguridad del artículo 73 b) iii) del ADPIC, que permite a los Estados, en casos de emergencia en las relaciones internacionales, adoptar las medidas necesarias para proteger sus intereses esenciales en materia de seguridad. Así, en aras de los intereses de seguridad sanitaria, podrían suspenderse los derechos de propiedad industrial con el fin de facilitar la importación o la producción local de los medicamentos y/o vacunas necesarios. El Estado que invoque esta excepción debe demostrar que la pandemia del COVID-19 constituye una "emergencia" en el significado de la norma, que la suspensión de los derechos de propiedad intelectual constituyen medidas necesarias para afrontar dichos "intereses esenciales de seguridad nacional" (interpretado como salud pública) y que existe una "no inverosímil" relación entre la suspensión de los derechos y el objetivo de proteger los intereses esenciales de seguridad nacional a la luz del principio de buena fe. Por otra parte, hay quienes sostienen que invocar este mecanismo presenta una serie de obstáculos prácticos e interpretativos. En el primer caso, porque no resuelve el problema de la falta de capacidad de fabricación nacional en algunos países; y en el segundo caso, en virtud de obstáculos que pueden derivar de otros acuerdos bilaterales de comercio y que imponen a los Estados signatarios ciertas obligaciones con referencia a la protección de los derechos de propiedad industrial, incluso la "renuncia" a ciertas flexibilidades del ADPIC (Bonadio, 2021; Kokawole Oke, 2020).

En favor de una suspensión generalizada de los derechos de propiedad intelectual también se mueve la propuesta presentada a principios de octubre de 2020 al Consejo de los ADPIC de la OMC por India y Sudáfrica (OMC, 2 de octubre de 2020), que sugiere maximizar las flexibilidades del acuerdo, permitiendo a los Estados miembros optar por una "renuncia" transitoria ${ }^{58}$ al ejercicio de los de-

58 De conformidad con el artículo IX.3 (b) del Acuerdo de Marrakech, por el que se establece que la OMC, en "circunstancias excepcionales", autoriza al 
rechos de patentes y otros derechos de propiedad intelectual relacionados con medicamentos, vacunas, dispositivos diagnósticos y otras tecnologías útiles en la prevención, la contención o el tratamiento del COVID-19. En lo específico, la exención propuesta abarca las obligaciones de cuatro secciones de la Parte II del ADPIC ${ }^{59}$ y tendría vigencia todo el tiempo que dure la pandemia, o hasta que se logre la inmunidad mediante una vacunación a nivel global.

Como fundamento de la iniciativa subyace, entre otros, la dificultad que muchos países en vías de desarrollo encuentran para utilizar las flexibilidades disponibles en el ADPIC, en mayor medida debido a la falta de un marco jurídico en el sistema nacional, como así también la manifiesta inviabilidad del mecanismo del artículo 31 bis del ADPIC para acelerar la producción y distribución de vacunas. A tal propósito -argumentan los Estados que apoyan esta iniciativa-, en los casos de países que no poseen capacidad para fabricar las vacunas u otra tecnología relacionada con el COVID-19, es necesario que la licencia obligatoria sea otorgada tanto en el país que requiere el suministro como en el país exportador que suministra el producto bajo la licencia obligatoria. Citando un ejemplo práctico de esto último (Shabalala, 2021), la cuestión no es si un país "X", que no tiene instalaciones de producción de vacunas (y, en muchos casos, los medicamentos ni siquiera están patentados allí), puede emitir una licencia obligatoria que permita a sus empresas nacionales fabricar las vacunas en ese país; el verdadero problema es si países " $Y$ " o " $Z$ ", con industrias farmacéuticas prósperas (donde es mucho más probable que los medicamentos estén patentados), pueden emitir una licencia obligatoria que permita a sus empresas exportar a "X". A mayor abundancia, las licencias obligatorias (si están disponibles en el derecho interno) son reguladas de manera distinta en cada Estado: algunos países requieren negociaciones previas con los titulares de

Consejo del ADPIC a eximir de una obligación impuesta a un país miembro de la OMC por el ADPIC, siempre que dicha exención cuente con el apoyo de las tres cuartas partes de los miembros.

59 ADPIC, Parte II, Normas relativas a la existencia, alcance y ejercicio de los derechos de Propiedad Intelectual (derecho de autor y los derechos conexos, diseños industriales, patentes y la protección de la información no divulgada). 
los derechos y otros las autorizan solo para uso público y no comercial. Todo ello -sugieren quienes apoyan la iniciativa- exigiría una meticulosa coordinación, máxime si varios países son involucrados, lo que en la práctica sería muy difícil de lograr, con el riesgo de frustrar los esfuerzos para satisfacer la demanda de una rápida producción y distribución mundial de vacunas y tecnologías para hacerle frente a la pandemia. Sin considerar que, como ponen de manifiesto aquellos que avalan la suspensión de los derechos de propiedad intelectual con base en el artículo 73 del ADPIC, las licencias obligatorias no resuelven el problema con respecto al uso no autorizado de otros derechos de propiedad intelectual o secretos industriales que podrían proteger la información o tecnología en cuestión.

Varios países en vías de desarrollo y menos desarrollados acogieron positivamente la propuesta, ${ }^{60}$ otros se mostraron disponibles a discutirla, ${ }^{61}$ mientras que otros manifestaron una rotunda oposición. ${ }^{62}$ Los países fuertemente opositores a la iniciativa, con importantes industrias farmacéuticas, objetan en primer lugar el rol clave de los derechos de propiedad intelectual en la investigación y la innovación, señalando que no hay indicios que demuestren que los derechos de propiedad intelectual hayan constituido un verdadero obstáculo para el acceso a los medicamentos y tecnologías relacionados con el COVID-19. En tal sentido, ha sido puesto de manifiesto que las dificultades en aplicar las excepciones o flexibilidades del ADPIC no derivan del acuerdo mismo, sino de falencias a nivel nacional por la falta de implementación en las respectivas legislaciones de la excepción de licencias obligatorias (Mercurio, 2021).

En esta perspectiva, si bien eliminar temporalmente los derechos de propiedad intelectual podría -en línea teórica- agilizar la producción y distribución de tecnología o conocimientos necesarios, en la práctica no resolvería las antes mencionadas dificultades de la

60 Entre ellos, Kenya, Eswatini, Mozambique y Pakistán. En América Latina, Argentina, Venezuela, Bolivia y Nicaragua, entre otros. A la fecha, más de cien países son favorables a la iniciativa.

61 Entre ellos, China, Ucrania, Chile, Ecuador, México, Turquía y El Salvador.

62 Entre ellos, Estados Unidos, Canadá, Norugega, Suiza y la Unión Europea. En America Latina, Brasil es uno de los países que no apoya la iniciativa. 
falta de capacidad para producir localmente dichas tecnologías y, sobretodo, a largo plazo afectaría negativamente en los incentivos a la innovación, impidiendo así el descubrimiento y el desarrollo de medicamentos o tecnologías que podrían relevarse útiles, incluso en la no remota posibilidad de pandemias futuras (Baachus, 2020).

Si esta medida es adecuada o no para resolver los problemas que la pandemia comporta, si es necesaria o excesiva, está siendo en la actualidad arduamente debatido tanto en el Consejo de los $\mathrm{ADPIC}^{63}$ como por académicos (Baachus, 2020; Mercurio, 2021), ${ }^{64}$ stakeholders (OMC, 2020d) ${ }^{65}$ y también en el debate políti$\mathrm{Co}^{66} \mathrm{y}$ ciudadano, pero un consenso de los países miembros de la OMC al respecto pareciera no estar a la orden del día. Las tesis que mueven el escepticismo de los países menos desarrollados basado en experiencias del pasado, como la pandemia de HIV, por un lado, y el temor de los países desarrollados a que la "restricción" de los derechos de propiedad intelectual se vuelva la regla y no la excepción, por el otro; ¿encontrarán su síntesis en la cooperación y solidaridad internacional?

En este sentido, la OMC tiene una lista completa de las distintas posiciones (OMC, 2021b).

63 Entre ellas, en el mes de diciembre de 2020, el 19 de enero de 2021 y de último en la reunión oficial del Consejo de los ADPIC los días 10 y 11 de marzo de 2021 (OMC, 2020d).

64 También argumentando que la propuesta de renuncia a la propiedad intelectual no resolvería todos los problemas que obstaculizan la producción y distribución de vacunas, véanse Caso (2021); Dehnne (14 de abril de 2020). Argumentando a favor de la concesión de licencias obligatorias, acompañada de un uso de patent pools y elevada coordinación a nivel internacional, puede ser la mejor solución, véanse: Muscolo y Luzzati (2021). Argumentando que una suspensión de los derechos de PI sería perjudicial para la innovación, véase: Hilty (2021). Argumentando que las vacunas deben ser un bien común, véanse: Red Argentina Investigadoras e Investigadores de Salud (2021); UNESCO (2021). Argumentando que las flexibilidades del ADPIC son insuficientes, véase: Ranjan (2021).

65 Como lo dan cuenta asociaciones del sector. Véanse: Larson (2021); McDonnell Boehnen Hulbert \& Berghoff LLP (2021).

66 Como lo dan cuenta diversas noticias a nivel global. Véanse: Ortega y Batres (2021); Vaccini, la mozione di maggioranza... (2021); Vaccini: appello politici UE... (2021). 


\section{Conclusión}

Los derechos de propiedad intelectual son herramientas fundamentales para el desarrollo tecnológico y para fomentar la innovación de invenciones socialmente desiderables. "Sin embargo, si se establece una vinculación entre los regímenes de propiedad intelectual con el derecho a la salud, la propiedad intelectual es un producto social y tiene una función social en tanto involucra un derecho humano fundamental" (Honorable Cámara de Diputados de la Nación, 2020). ${ }^{67}$ De allí que en un contexto como el actual la justificación económica utilitarista dentro de un marco altruista más amplio, en el que el beneficio social funciona como el objetivo último, que subyace al sistema de patentes (Bonadio y Baldini, 2020), ${ }^{68}$ puede conducir a resultados éticamente cuestionables e, incluso, contrarios a la finalidad última de los derechos de propiedad industrial, es decir, el desarrollo tecnológico para el bienestar social.

Como se ha presentado a lo largo de este artículo, lograr el justo equilibrio entre las normas sobre la propiedad intelectual y, al mismo tiempo, promover el acceso a los medicamentos que salvan vidas es una cuestión delicada. En beneficio colectivo, ni los derechos de pro-

67 Cabe recordar las disposiciones establecidas en el Pacto Internacional de Derecchos Económicos, Sociales y Culturales (PIDESC), que, precisamente en su artículo 12, provee la norma más comprensiva sobre el derecho a la salud del derecho internacional de los derechos humanos, el cual hace hincapié en el acceso equitativo a la asistencia sanitaria y en unas garantías mínimas de asistencia sanitaria en caso de enfermedad. Así, además de consagrar el derecho a la salud, recoge las observaciones generales elaboradas por el Comité DESC del PIDESC en relación con el derecho a la salud. Este tratado, en su párrafo 43, consagra una serie de obligaciones inderogables que, en ningún caso, puede el Estado signatario dejar de cumplir y que son inderogables: "[...] d) Facilitar medicamentos esenciales, según las definiciones periódicas de la OMS; e) Velar por una distribución equitativa de todas las instalaciones, bienes y servicios de salud; f) Adoptar y aplicar, sobre la base de las pruebas epidemiológicas, una estrategia y un plan de acción nacional de salud pública” (cf. Honorable Cámara de Diputados de la Nación, 2020).

68 Estos autores argumentan sobre la imposibilidad, en tiempos de emergencia, de sostener las teorías económicas que justifican los derechos de PI como la única fuente legítima en casos de conflictos entre el bienestar individual y el bienestar social. 
piedad intelectual deben convertirse en obstáculos legales ni los incentivos que son esenciales para inspirar las innovaciones deben eliminarse. La búsqueda de este equilibrio debe orientarse en la cooperación.

Por ello, se hace necesario que se establezcan mecanismos de cooperación internacional que faciliten el acceso y la distribución de medicamentos, tecnología médica esencial y -en definitiva- el uso de los avances científicos y técnicos para satisfacer las necesidades derivadas de la actual pandemia (Barbosa, 2019, p. 1635), contribuyendo al mismo tiempo a delinear un cuadro reglamentario para hacer frente a otras (no improbables) pandemias futuras.

Por otra parte, también los actores privados y la comunidad científica involucrados en la creación de invenciones fundamentales para contrastar la pandemia deben asumir esta responsabilidad social, como lo han demostrado muchas de las iniciativas voluntarias y colaboraciones entre diferentes entidades privadas y públicas.

El sistema de protección de los derechos de propiedad industrial se diseñó para contribuir al desarrollo, fomentando la inversión en nuevas tecnologías para lograr el bienestar colectivo. Flexibilizar sus reglas y promover la participación colectiva en la creación y diseminación de conocimiento y tecnología es la forma de mantener esa contribución en el escenario actual (Duro, 2020).

\section{Bibliografía}

Abbott, F. M. (2002). The TRIPs agreement, access to medicines, and the WTO Doha ministerial conference. The Journal of World Intellectual Property, 5(1), 15-52.

Abbott, F. M. (2020). The TRIPS Agreement Article 73 Security Exceptions and the COVID-19 Pandemic. Research Paper. http://dx.doi.org/10.2139/ ssrn.3682260.

Akpotaire, U. B. (2010). HIV and AIDS in Africa: Compulsory Licensing Under TRIPS and DOHA Declaration. http://dx.doi.org/10.2139/ssrn.1719555.

Argentina pide licencia compulsiva de droga contra gripe aviar. (18 de octubre de 2005). La Nación. https://www.nacion.com/economia/argentina-pide-licencia-compulsiva-de-droga-contra-gripe-aviar/NZXJX7NXBFELHHYUZTLUSLDAY4/story/.

Baachus, J. (2020). An Unnecessary Proposal: A WTO Waiver of Intellectual Property Rights for COVID-19 Vaccines. Cato Institute, Free Trade Bulletin 78. 
Barbosa, D. (2019). Tratado da Propriedade Intelectual (2a ed.). Lumen Juris Editora. Binctin, N., Bourdon, R., Dhenne, M. y Vial, L. (2020). Feedback on the Intellectual Property Action Plan Roadmap of the European Commission. Institut Stanislas De Boufflers.

Bonadio, E. (2012). Compulsory licensing of patents: the Bayer/Natco case. European Intellectual Property Review, (10), 719-728.

Bonadio, E. (24 de febrero de 2021). Intellecual Property and COVID-19 medicines: Why a WTO waiver may not be enough? The Conversation. https:// theconversation.com/intellectual-property-and-covid-19-medicines-why-awto-waiver-may-not-be-enough-155920.

Bonadio, E. y Baldini, A. (2020). COVID-19, Patents and the never-ending tension between proprietary rights and the protection of public health. European Journal of Risk Regulation, 11(2), 390-395.

Bundesministerium der Justiz und für Verbraucherschutz. (2000). Ley para la Prevención y Control de Enfermedades Infecciosas en Humanos. https://www. gesetze-im-internet.de/ifsg/index.html?_sm_au_=iVVvns5WHQ11sMDPvMFckK0232C0F.

Carr, D. (31 de enero de 2020). Sharing research data and findings relevant to the novel coronavirus (COVID-19) outbreak. Wellcome. https://wellcome.org/coronavirus-covid-19/open-data.

Caso, R. (8 de febrero de 2021). Vaccini proprietà di pochi o bene comune dell'umanità? https:/www.robertocaso.it/2021/02/08/vaccini-proprieta-di-pochi-o-bene-comune-dellumanita/.

Cassata, C. (11 de marzo de 2021). Here's How It Was Possible to Develop COVID-19 Vaccines So Quickly. Healthline. https://www.healthline.com/health-news/heres-how-it-was-possible-to-develop-covid-19-vaccines-so-quickly.

Champ, P. y Attaran, A. (2002). Patent rights and local working under WTO TRIPS agreement: An analysis of the US-Brazil patent dispute. Yale Journal of International Law, 27(2), 365-393.

Choy, K. Y. y Lo, J. Y. (2020). COVID-19 Patent controversy. Hong Kong Lawyer. The official Journal of the law society of Hong Kong. http://www.hk-lawyer.org/ content/covid-19-patent-controversy.

Contreras, J. L. (2021). The Open COVID Pledge: Design, Implementation and Preliminary Assessment of an Intellectual Property Commons. University of Utah College of Law Research Paper No. 416. https://ssrn.com/abstract $=3780850$.

Correa, C. M. (2002). Public health and intellectual property rights. Global Social Policy, 2(3), 261-278.

Correa, C. M. (2005). TRIPS agreement and access to drugs in developing countries. SUR-International Journal on Human Rights, 2(3).

Correa, C. M. y Velásquez, G. (2019). Access to Medicines: Experiences with Compulsory Licenses and Government Use-The Case of Hepatitis C. South Centre, Research Paper 85. 
Desantes, M. (2020). The Disruptive Nature of the So-Called Fourth Industrial Revolution for Intellectual Property: Moving Societal Changes from Linear to Exponential. En Heath, C., Kamperman Sanders, A. y Moerland, A. (Eds.), Intellectual Property Law and the Fourth Industrial Revolution ( $p$ p. 3-28). Wolters Kluwer.

Dhenne, M. (14 de abril de 2020). Compulsory licensing and COVID-19 vaccines: when fake news spoil the public debate. Kluwer Patent Blog. http://patentblog. kluweriplaw.com/2021/04/14/compulsory-licensing-and-covid-19-vaccineswhen-fake-news-spoil-the-public-debate/.

Dhenne, M. (1 de mayo de 2020). COVID-19, patents and access to healthcare: a French perspective. http://dx.doi.org/10.2139/ssrn.3614409.

DiMasi, J. A., Grabowski, H. G. y Hansen, R. W. (2016). Innovation in the pharmaceutical industry: new estimates of R\&D costs. Journal of Health Economics, (47), 20-33.

Docdot Provides Healthcare Professionals with a Medical Grade COVID-19 Remote Diagnosis App. (8 de mayo de 2021). The Journal of mHealth. https://thejournalofmhealth.com/docdot-provides-healthcare-professionals-with-a-medical-grade-covid-19-remote-diagnosis-app/.

Duro, L. (15 de mayo de 2020). Como evitar violaçóes aos direitos de propriedade intelectual na pandemia. Consultor Jurídico. https:/www.conjur.com. br/2020-mai-15/laura-duro-covid-19-direitos-propriedade-intelectual.

Easy COVID-19. (2020). Isinnova. https://www.isinnova.it/easy-covid19.

European Patent Office. (2018). Compulsory licensing in Europe. https://www.epo. org/learning/materials/compulsory-licensing-in-europe.html.

European Patent Office. (2020). European patent applications. https://www.epo. org/about-us/annual-reports-statistics/statistics/2020/statistics/patent-applications.html\#tab3.

Fisher, W. (2001). Theories of intellectual property. Cambridge.

Hilty, R. (15 de marzo de 2021). Interfering with patent protection means playing with fire. Max-Planck-Gesellschaft. https://www.mpg.de/16579491/patent-protection-vaccines-covid-10-reto-hilty.

Hohne, C. (8 de marzo de 2019). Compulsory licenses in Germany: a tool for licensing negotiations? European Pharmaceutical Review. https:/www.europeanpharmaceuticalreview.com/article/84768/compulsory-licenses-in-germany-a-tool-for-licensing-negotiations/.

Honorable Cámara de Diputados de la Nación. (22 de julio de 2020). Proyecto de Resolución. Expediente 3691-D-2020. https://www.diputados.gob.ar/proyectos/proyecto.jsp? exp=3691-D-2020.

Hooker, L. y Palumbo, D. (2020). COVID vaccines: Will companies make bumper profits? BBC News. https://www.bbc.com/news/business-55170756.

Instituto Nacional de Propiedad Intelectual de Chile. (2020). Resolución No 896. https://www.camara.cl/verDoc.aspx?prmId=3885\&prmDestinoId=3\&prmTipo=RESOLUCIONENVIO. 
International Federation of Pharmaceutical Manufacturers \& Associations. (2019). The Complex Journey of a Vaccine Part III. The Steps Behind Developing a New Vaccine. https:/www.ifpma.org/wp-content/uploads/2019/07/ IFPMA-ComplexJourney-2019_Stage-5_Web_High-Res.pdf.

Isaacson, W. (11 de enero de 2021). mRNA Technology Gave Us the First COVID-19 Vaccines. It Could Also Upend the Drug Industry. Time. https:// time.com/5927342/mrna-covid-vaccine/.

Joffre, T. (16 de marzo de 2020). Israel Health Ministry approves experimental treatments for coronavirus. The Jerusalem Post. https://www.jpost.com/Israel-News/ Health-Ministry-approves-experimental-treatments-for-coronavirus-621209.

Jones, R. (2020). Ten innovations in the fight against COVID-19. Raconteur. https:/www.raconteur.net/healthcare/healthcare-innovation-covid/.

Jordan, J. y Weispfenning, R. (2020). Medtronic Shares Ventilation Design Specifcations to Accelerate Efforts to Increase Global Ventilator Production. Medtronic. https://newsroom.medtronic.com/news-releases/news-release-details/medtronic-shares-ventilation-design-specifications-accelerate.

Kokawole Oke, E. (2020). Is the national security exception in the TRIPS agreement a realistic option in confronting COVID-19? Ejil:Talk! https://www.ejiltalk. $\mathrm{org}$ /is-the-national-security-exception-in-the-trips-agreement-a-realistic-option-in-confronting-covid-19/.

Larson, N. (23 de febrero de 2021). Waiving IP will not boost vaccine production. Medical Press. https://medicalxpress.com/news/2021-02-waiving-ip-boost-vaccine-production.html.

Letter to Dr Tedros Adhanom Ghebreyesus. (23 de marzo de 2020). https:// www.keionline.org/wp-content/uploads/President-MoH-Costa-Rica-Dr-Tedros-WHO24March2020.pdf.

Lichtman, D. (2018). The Central Assumptions of Patent Law: A Response to Ana Santos Rutschman's IP Preparedness for Outbreak Diseases. UCLA Law Review, (65), 1268-1275.

Mancini, D. P. y Kuchler, H. (23 de marzo de 2020). AbbVie drops patent rights for Kaletra antiviral treatment. Financial Times. https://www.ft.com/content/5a7a9658-6d1f-11ea-89df-41bea055720b.

Maurer, S. M. (2015). Intellectual Property Incentives: Economics and Policy Implications. En Dreyfuss, R. y Pila, J. (Eds.), The Oxford Handbook of Intellectual Property Law. Oxford University Press.

McDonnell Boehnen Hulbert \& Berghoff LLP. (12 de marzo de 2021). BIO and PhRMA Urge Biden Administration to Oppose Proposed WTO TRIPS Waiver. JDSupra. https:/www.jdsupra.com/legalnews/bio-and-phrma-urge-biden-administration-7725255/.

McGahan, A. M., Bogers, M. L., Chesbrough, H. y Holgersson, M. (26 de noviembre de 2020). Tackling Societal Challenges with Open Innovation. California Management Review. https://doi.org/10.1177/0008125620973713. 
McNabb, M. (2021). Draganfly's COVID-19 Vaccine Delivery Solution. Drone Life. https://dronelife.com/2021/02/05/draganflys-covid-19-vaccine-delivery-solution/.

Mercurio, B. (2021). WTO Waiver from Intellectual Property Protection for COVID-19 Vaccines and Treatments: A Critical Review. Virginia Journal of International Law Online (forthcoming 2021). http://dx.doi.org/10.2139/ ssrn.3789820.

Milken Institute. (2021). COVID-19 Treatment and Vaccine Tracker. https:// covid-19tracker.milkeninstitute.org/\#vaccines_.

Morgan, B. (2021). 10 Examples OfHealthcare Innovation In The Face OfCOVID. Forbes. https://www.forbes.com/sites/blakemorgan/2021/02/01/10-examples-of-healthcare-innovation-in-the-face-of-covid/?sh=90627a8680d4.

Muscolo G. y Luzzati A. (2021). Pharma \& COVID-19: An Overview Of Eu And National Case Law. Concurrences. https://www.concurrences.com/en/bulletin/special-issues/pharma-covid-19/pharma-covid-19-an-overview-of-eu-andnational-case-law-99409-en\#nb13.

Organización Mundial de la Salud. (2002). Repercusiones de la declaración de Doha relativa al acuerdo sobre los ADPIC y la salud pública / Carlos M. Correa. https:// apps.who.int/iris/handle/10665/68356.

Organización Mundial de la Salud. (2020a). Alocución de apertura del Director General de la OMS en la rueda de prensa para las misiones diplomáticas sobre la COVID-19 celebrada el 12 de marzo de 2020. https://www.who.int/es/director-general/speeches/detail/who-director-general-s-opening-remarks-at-themission-briefing-on-covid-19---12-march-2020.

Organización Mundial de la Salud. (2020b). Boost for global response to COVID-19 as economies worldwide formally sign up to COVAX facility. https://www.who. $\mathrm{int} /$ news/item/21-09-2020-boost-for-global-response-to-covid-19-as-economies-worldwide-formally-sign-up-to-covax-facility.

Organización Mundial de la Salud. (2020c). COVID-19 Technology Access Pool. https:/www.who.int/initiatives/covid-19-technology-access-pool.

Organización Mundial de la Salud. (2020d). Members to continue discussion on proposal for temporary IP waiver in response to COVID-19. https://www.wto. org/english/news_e/news20_e/trip_10dec20_e.htm.

Organización Mundial de la Salud. (2020e). Solidarity Call to Action. https:// www.who.int/emergencies/diseases/novel-coronavirus-2019/global-research-on-novel-coronavirus-2019-ncov/covid-19-technology-access-pool/ solidarity-call-to-action.

Organización Mundial de la Salud. (2021a). Coronavirus (COVID-19). https:// covid19.who.int/.

Organización Mundial de la Salud. (2021b). Members discuss TRIPS waiver request, exchange views on IP role amid a pandemic. https://www.wto.org/english/ news_e/news21_e/trip_23feb21_e.htm.

Organización Mundial del Comercio. (2001). Declaración relativa al acuerdo sobre 
los ADPIC y la salud pública. https://www.wto.org/spanish/thewto_s/minist_s/min01_s/mindecl_trips_s.htm.

Organización Mundial del Comercio. (2003). Implementation of Paragraph 6 of the Doha Declaration on the TRIPS Agreement and Public Health. https://www. wto.org/english/tratop_e/trips_e/implem_para6_e.htm.

Organización Mundial del Comercio. (2005). Compulsory Licensing of Pharmaceuticals and TRIPS. https://www.wto.org/english/tratop_e/trips_e/public_health_faq_e.htm.

Organización Mundial del Comercio. (2020). COVID-19: medidas relativas a los derechos de propiedad intelectual relacionados con el comercio. https://www.wto. org/english/tratop_e/covid19_e/ipd_measures_s.pdf.

Organización Mundial del Comercio. (2 de octubre de 2020). Waiver from Certain Provisions of the TRIPS Agreement for the Prevention, Containment and Treatment of COVID-19. Communication from India and South Africa. https://docs.wto.org/dol2fe/Pages/SS/directdoc.aspx?filename=q:/IP/C/W669. pdf\&Open=True” It “_blank.

Ortega, E. y Batres, O. (2021), Mayoría absoluta del No en el Congreso a liberar patentes de vacunas COVID. Redacción Médica. https://www.redaccionmedica.com/secciones/parlamentarios/liberar-patentes-vacunas-covid-congreso-mayoria-absoluta-no-6290.

Peters, D. (30 de mayo de 2020). WHO Recognizes the Open COVID Pledge as a Means to Advance Research and Science in the Fight Against COVID-19. Open Covid Pledge. https://opencovidpledge.org/2020/05/30/who-recognizes-the-open-covidpledge-as-a-means-to-advance-research-and-science-in-the-fight-against-covid-19.

Ragavan, S. (2012). Patent and trade disparities in developing countries. Oxford University Press.

Ramacciotti, E. y Fratti, A. (2020). Risvolti brevettuali dell'emergenza sanitaria: le attuali ipotesi risolutive. Il quotidiano Giuridico. Wolters Kluwer.

Ramanujam, P. y Goyal, Y. (2014). One view of compulsory licensing: Comparative perspectives from India and Canada. Marquette Intellectual Property Law Review, 18(2), 369.

Ranjan, P. (2021). The Case for Waiving Intellectual Property Protection for Covid-19 Vaccines. Observer Research Foundation. https://www.orfonline.org/research/ the-case-for-waiving-intellectual-property-protection-for-covid-19-vaccines.

Rathod, S. K. (2017). Compulsory licences on pharmaceutical patents in India: A short article. Journal of Generic Medicines, 13(3), 108-113.

Red Argentina Investigadoras e Investigadores de Salud. (2021). Vacunas contra la COVID-19. ¿Bienes públicos o de mercado? Post Note Número 02. https:// drive.google.com/file/d/1Cd-A_pi0fDB_t9Pa8MkCBbbiZsJA0R3E/view.

Regattieri Oliveira, J. (2020). COVID-19, vacinas e a Licença Compulsória de Patentes. Espírito Santo. https://www.oabes.org.br/artigos/covid-19-vacinas-e-a-licenca-compulsoria-de-patentes-58.html.

Ritchie, H., Ortiz-Ospina, E., Beltekian, D., Mathieu, E., Hasell, J., Macdonald, 
B., Giattino, C., Appel, C. y Roser, M. (2021). Coronavirus (COVID-19) vaccinations. Statistics and research. https://ourworldindata.org/covid-vaccinations. Rutschman, A. S. (2018). IP preparedness for outbreak diseases. UCLA Law Review, (65), 1200-1266.

Safi, M. (2021). Oxford AstraZeneca Covid vaccine was 97\% publicly funded. The Guardian. https://www.theguardian.com/science/2021/apr/15/oxfordastrazeneca-covid-vaccine-research-was-97-publicly-funded.

Schötz, G. y Rapela, M. (2020). Covid-19, Derechos de Propiedad Intelectual y Licencias Obligatorias. Revista Jurídica La Ley, 2020-C.

Shabalala D. (2021). How to get COVID-19 vaccines to poor countries - and still keep patent benefits for drug makers. The Conversation. https://theconversation.com/how-to-get-covid-19-vaccines-to-poor-countries-and-still-keep-patent-benefits-for-drugmakers-158384.

Standing Committee on the Law of Patents. (2019). Thirtieth Session. Ginebra, 24 al 27 de junio de 2019. https://www.wipo.int/meetings/en/details.jsp?meeting_id $=50419$.

UNESCO. (2021). Unesco calls COVID-19 vaccines be considered global public good. https://en.unesco.org/news/unesco-calls-covid-19-vaccines-be-consideredglobal-public-good.

Vaccini, la mozione di maggioranza alla Camera impegna il governo (che è contrario) a spingere per la deroga temporanea sui brevetti. (24 de marzo de 2021). Il fatto quotidiano. https://www.ilfattoquotidiano.it/2021/03/24/vaccini-la-mozione-di-maggioranza-alla-camera-impegna-il-governo-che-e-contrario-a-spingere-per-la-deroga-temporanea-sui-brevetti/6144140/.

Vaccini: appello politici UE per la sospensione brevetti. (2021). Ait Europa. https://www. ansa.it/europa/notizie/rubriche/voceeurodeputati/2021/03/23/vaccini-appello-politici-a-ue-per-sospensione-brevetti_0a6e72dd-31e7-43c4-8f4a-1a63f3a2bc3b.html.

Vinci, A. (18 de marzo de 2020). Coronavirus, mancano le valvole per i respiratori: ingegnere ne dona 100 prodotte con la stampa 3D. Corriere della Sera. https://www.corriere.it/tecnologia/20_marzo_18/coronavirus-mancano-valvole-respiratori-ingegnere-ne-dona-100-prodotte-la-stampa-3d-f5593624-68 84-11ea-9725-c592292e4a85.shtml.

Weise, E. y Weintraub, K. (7 de febrero de 2021). How COVID vaccine made step step journey Pfizer dose. USA Today. https://eu.usatoday.com/in-depth/ news/health/2021/02/07/how-covid-vaccine-made-step-step-journey-pfizerdose/4371693001/.

Wilkof, N. (2020). The process may (or may not) be the product: trade secrets and COVID research. The IPKat. https://ipkitten.blogspot.com/2020/08/the-process-may-or-may-not-be-product.html.

Zucoloto, G., Miranda, P. y Porto, P. (2020). A propriedade industrial pode limitar o combate à pandemia? https://www.ipea.gov.br/. 